\title{
СУТЬ ОЦЕНКИ ИМУЩЕСТВЕННЫХ КОМПЛЕКСОВ
}

\section{Виктория Анатольевна Дементьева}

Сибирский государственный университет геосистем и технологий, 630108, Россия, г. Новосибирск, ул. Плахотного, 10, обучающийся, тел. (905)946-99-89, e-mail: d-v-a@bk.ru

В статье дается понятие оценки имущественных комплексов, исследуются этапы оценки имущественных комплексов, описываются субъекты, объекты, инициаторы процедуры, раскрывается сущность оценки имущественных комплексов.

Ключевые слова: оценка имущественных комплексов, оценщик, заказчик, процедура

\section{ESSENCE OF ASSESSMENT OF PROPERTY COMPLEXES}

\section{Victoria A. Dementyeva}

Siberian State University of Geosystems and Technologies, 10, Plakhotnogo St., Novosibirsk, 630108, Russia, Student, phone: (905)946-99-89, e-mail: d-v-a@bk.ru

The article gives the concept of assessing property complexes, examines the stages of assessing property complexes, describes the subjects, objects and initiators of the procedure, discloses the essence of assessing property complexes.

Keywords: appraisal of property complexes, appraiser, customer, procedure

Самой объемной, затратной и долгой услугой оценщика является оценка имущественных комплексов. А происходит это, потому что в нее входит оценка не одного объекта, а совокупность объектов, которые являются собственностью какого-то лица в целях предпринимательской деятельности. Данная процедура является обязательной и состоит из определения денежного выражения совокупности правовых, недвижимых и движимых объектов, которые находятся на балансе юридического лица и задействованы в предпринимательской деятельности [1]. В каких ситуациях применяется данная процедура представлено на рис. 1.

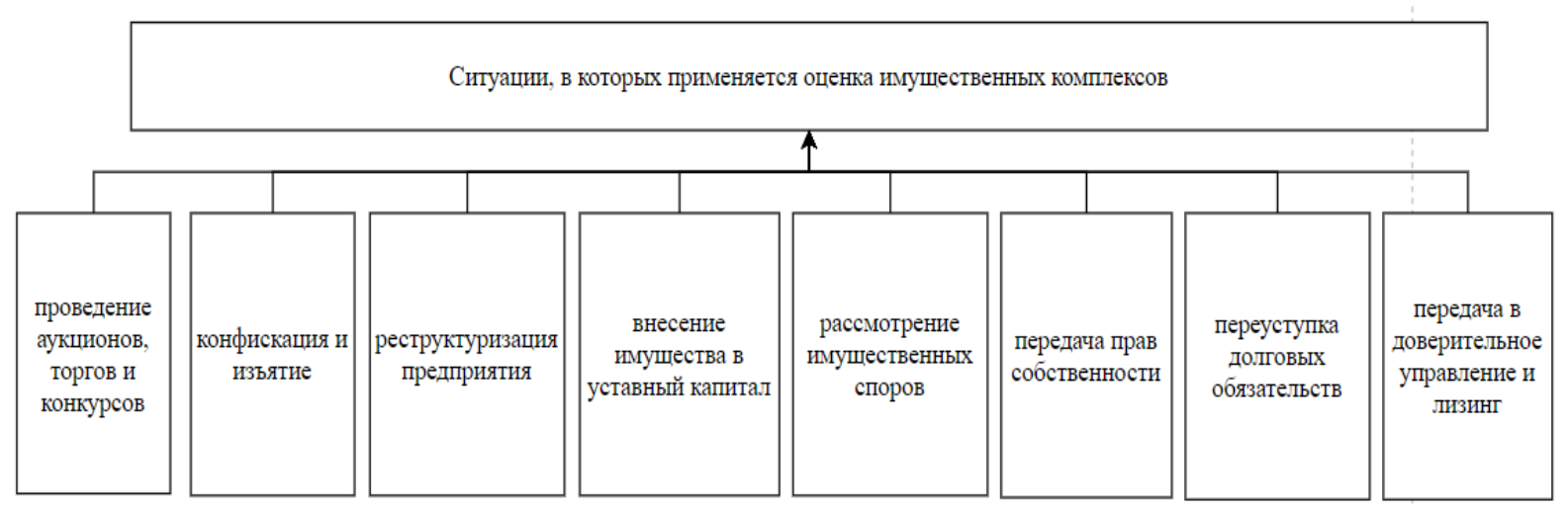

Рис. 1. Ситуации, в которых необходима оценка имущественных комплексов 
Субъектами процедуры могут быть физические и юридические заинтересованные лица, частный оценщик или представитель компании. На рис. 2 рассмотрены инициаторы определения стоимости объекта.

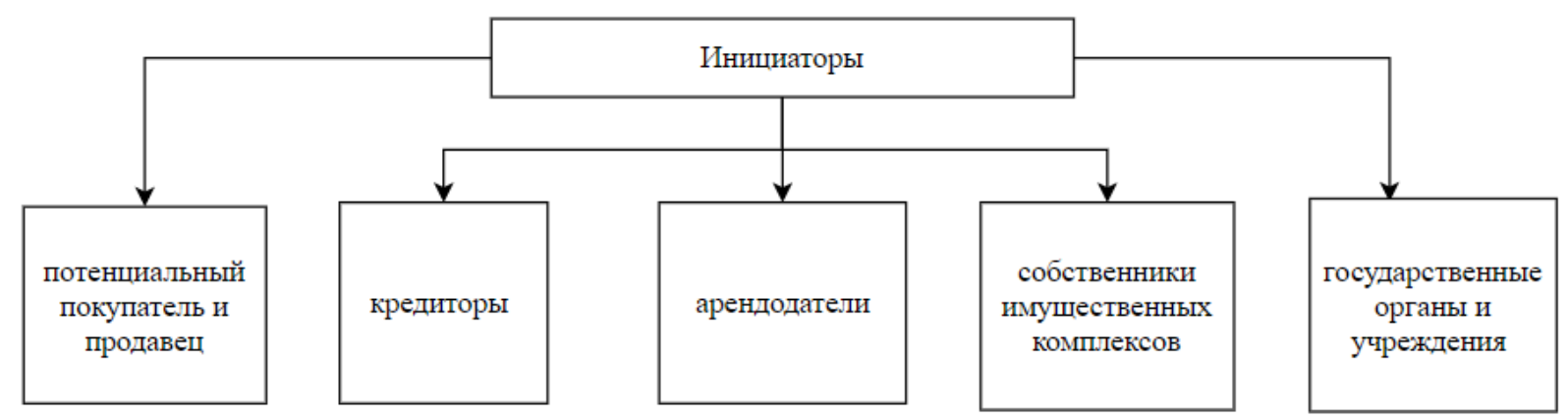

Рис. 2. Инициаторы определения стоимости объекта

Объектами оценки являются:

- земельные участки;

- недвижимость;

- ценные бумаги;

- оборудование;

- транспорт;

- компании, организации, предприятия;

- интеллектуальная собственность;

- офисы и организации на удаленных расстояниях, относящиеся к одному юридическому лицу.

Проводить оценку может только квалифицированное лицо, которое имеет соответствующее разрешение и регистрацию. В некоторых случаях на объект требуется не один оценщик, а целая команда [2].

Для начала процедуры оценки нужно подать заявление частному оценщику или в оценочную компанию. После этого оценщик или компания отправляет заказчику счет на проведение процедуры и проект договора. Далее, при обоюдном согласии, подписывается договор об оказании услуги и заказчик оплачивает услугу. После всех действий оценщик исследует объект для того, чтобы определить его ценность. При исследовании оценщику нужны следующие документы от заказчика:

- отчеты о результатах финансовой деятельности за предыдущие 5 лет;

- ведомость об имеющихся основных фондах;

- паспорта БТИ на здания и сооружения, входящие в ИК;

- штатное расписание;

- учредительные документы и устав организации;

- информация о материальных и нематериальных активах;

- сведения о дебиторской и кредиторской задолженностях. 
После исследования оценщик приступает к основной деятельности - определению стоимости объектов, используя различные подходы, входящие в них методы оценки. Он может использовать несколько методов, для более точных результатов. Данные методы представлены на рис. 3.

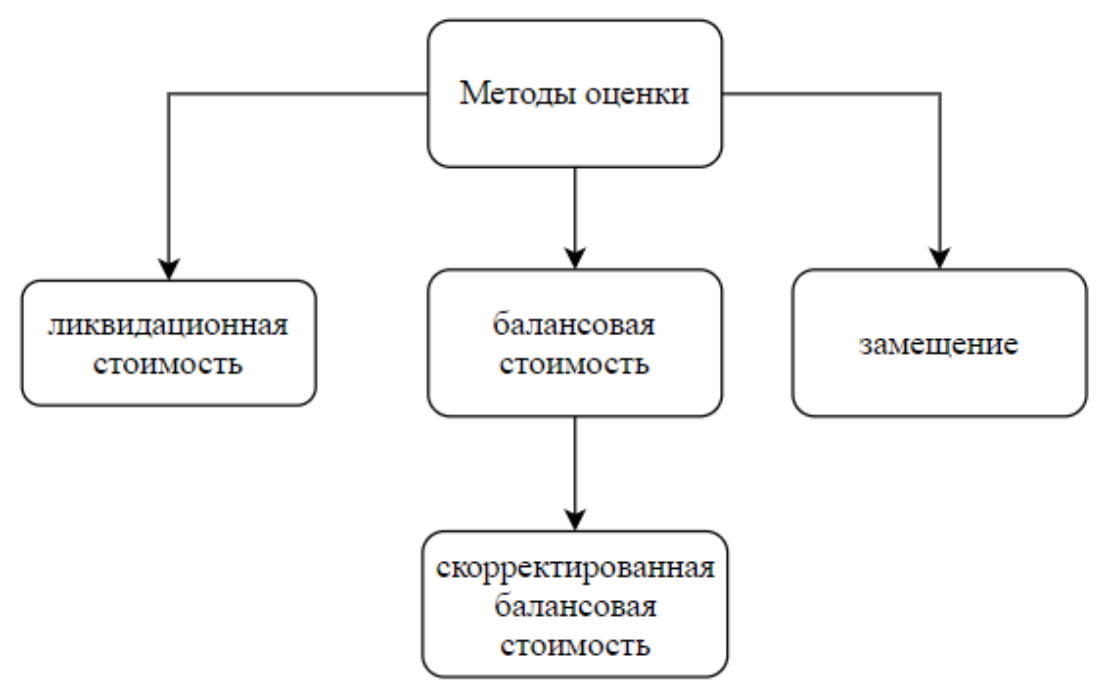

Рис. 3. Методы оценки

В конце процедуры оценщик формирует отчет, в котором отображены все действия специалиста во время оценки объектов. Данный отчет имеет юридическую силу и действует в течение полугода.

Если работа специалиста сделана не точно, то в данном случае она оспаривается в судебном порядке в соответствии с законом [3].

В связи с Федеральным законом от 31.07.2020 № 269 «О внесении изменений в отдельные законодательные акты Российской Федерации", в части изменений в Федеральный закон от 3 июля 2016 г. № 237-Ф3 «О государственной кадастровой оценке» (ФЗ о ГКО) изменилось следующее:

- кадастровая оценка теперь проводится через 4 года после проведения последней;

- можно проводить только два вида кампаний по оценке: одновременно по всем объектам капитального строительства либо одновременно по всем земельным участкам;

- замечания к проекту представить в срок до 30 календарных дней;

- заявление на исправление теперь можно будет подать лишь после внесения стоимости в ЕГРН;

- с 2023 г. процедуру пересмотра кадастровой стоимости в размере рыночной стоимости в региональной комиссии или суде меняют на процедуру установления кадастровой стоимости в размере рыночной стоимости самим бюджетным учреждением по заявлению, т.е. теперь по новой процедуре прямое обращение в суд исключено, сначала надо идти в бюджетное учреждение; 
- вместо внеочередной государственной кадастровой оценки, ввели процедуру ежегодного мониторинга рынка недвижимости и автоматического уменьшения кадастровой стоимости, если индекс рынка недвижимости падает более чем на $30 \%$ по сравнению с первым годом действия результатов государственной оценки [4].

\section{БИБЛИОГРАФИЧЕСКИЙ СПИСОК}

1. Григорьев В.В., Островкин И.М. Оценка предприятий: имущественный подход: Учеб. - практ. пособие. М: Дело, 1998 г. - 224 с.

2. Оценка стоимости предприятия (бизнеса) : Учеб. пособие / Под ред. Н.А. Абдулаева, Н.А. Колайко. М.: Экмос, 2000. - 346 с.

3. Тарасевич А.Л. Банкротство банка: процедуры и механизм реализации. СПб.: Изд-во С.-Петерб. ун-та экономики и финансов, 1998. - 301 с.

4. Федеральный закон от 31.07.2020 N 269-Ф3 "О внесении изменений в отдельные законодательные акты Российской Федерации" [Электронный ресурс]. - Режим доступа: http://www.consultant.ru/document/cons_doc_LAW_358790/46b4b351a6eb6bf3c553d41 eb663 $011 \mathrm{c} 2 \mathrm{cb} 38810 /$.

(C) В. А. Дементьева, 2021 